\title{
9. Congenital Conditions
}

\section{Congenital conditions among stillborn and liveborn infants}

From 1 January 1998, doctors, hospitals and laboratories are required under the NSW Public Health Act 1991 to notify certain congenital conditions detected during pregnancy or in a baby up to one year of age. Information reported is included in the NSW Register of Congenital Conditions, formerly known as the NSW Birth Defects Register.

There are three types of conditions that are reported to the Register:

- Conditions that affect the growth, development and health of the baby that are present before birth, such as cleft lip, dislocated hip and problems with the development of the heart, lungs or other organs

- Conditions due to changes in the number of the baby's chromosomes, such as Down syndrome

- Four conditions due to changes in the baby's inherited genetic information: cystic fibrosis, phenylketonuria, congenital hypothyroidism and thalassaemia major.

Descriptions of some common congenital conditions are shown in Appendix 1. A list of common exclusions is shown in Appendix 2.

This chapter reports congenital conditions detected during pregnancy or in the first year of life for 2003-2008 and congenital conditions detected during pregnancy or at birth for 2009.

\section{Trends in reported congenital conditions}

Between 2003 and 2008, 1.8\% to $2.1 \%$ of infants were reported to have congenital conditions, (Table 103). In 2009, 831 cases of congenital conditions detected during pregnancy or at birth have been reported to date.
Table 103. Cases of congenital conditions, NSW 2003-2009\#

\begin{tabular}{cccc} 
Year & $\begin{array}{c}\text { Cases of congenital } \\
\text { conditions }\end{array}$ & Births & $\begin{array}{c}\text { Rate/1000 } \\
\text { births }\end{array}$ \\
\hline 2003 & No. & No. & \\
2004 & 1756 & 85405 & 20.6 \\
2005 & 1751 & 84607 & 20.7 \\
2006 & 1617 & 89337 & 18.1 \\
2007 & 1768 & 91554 & 19.3 \\
2008 & 1829 & 94640 & 19.3 \\
2009 & 1881 & 94874 & 19.8 \\
\hline
\end{tabular}

Source: NSW Register of Congenital Conditions (HOIST). Centre for Epidemiology and Research, NSW Ministry of Health.

\# For 2003-2008, cases reported during pregnancy and up to one year of age are

included. For 2009, cases reported during pregnancy or at birth are included.

\section{Congenital conditions by diagnostic category}

The most common categories of congenital conditions for stillborn and live born babies are presented in Table 104. Congenital conditions are classified using the British Paediatric Association (BPA) Classification of Diseases, which is primarily organised by body system. For infants with more than one condition, each condition is counted separately. The number of congenital conditions reported therefore exceeds the number of affected infants.

In 2002-2008, conditions of the cardiovascular system were most commonly reported, followed by conditions of the musculoskeletal system and conditions of the genitourinary system (Table 104). This is a similar pattern to previous years. In 2008, the overall rate of conditions was lower than the previous 5 years (36.0 versus 44.0 per 1,000 respectively). 
Table 104. Congenital conditions among stillbirths and liveborn infants by diagnostic category, NSW 2003-2009\#

\begin{tabular}{|c|c|c|c|c|c|c|c|c|}
\hline \multirow[t]{2}{*}{ Diagnostic category } & \multicolumn{4}{|c|}{ No. conditions } & \multicolumn{4}{|c|}{ Rate/1,000 births } \\
\hline & 2003-2007 & 2008 & 2009 & 2003-2009 & 2003-2007 & 2008 & 2009 & 2003-2009 \\
\hline \multicolumn{9}{|l|}{ Nervous system } \\
\hline Anencephaly & 51 & 7 & 5 & 63 & 0.1 & 0.1 & 0.1 & 0.1 \\
\hline Spina Bifida & 138 & 38 & 27 & 203 & 0.4 & 0.4 & 0.3 & 0.3 \\
\hline Encephalocele & 30 & 8 & 5 & 43 & 0.1 & 0.1 & 0.1 & 0.1 \\
\hline Microcephaly & 101 & 19 & 10 & 130 & 0.3 & 0.2 & 0.1 & 0.2 \\
\hline Congenital hydrocephalus & 175 & 33 & 23 & 231 & 0.5 & 0.3 & 0.2 & 0.4 \\
\hline Other nervous system anomalies & 291 & 76 & 42 & 409 & 0.8 & 0.8 & 0.4 & 0.6 \\
\hline TOTAL & 786 & 181 & 112 & 1079 & 2.2 & 1.9 & 1.2 & 1.7 \\
\hline \multicolumn{9}{|l|}{ Eye } \\
\hline Anophthalmos-microphthalmos & 58 & 8 & 11 & 77 & 0.2 & 0.1 & 0.1 & 0.1 \\
\hline Buphthalmos-congenital glaucoma & 27 & 7 & 2 & 36 & 0.1 & 0.1 & 0.0 & 0.1 \\
\hline Congenital cataract & 86 & 12 & 4 & 102 & 0.2 & 0.1 & 0.0 & 0.2 \\
\hline Other eye anomalies & 180 & 45 & 11 & 236 & 0.5 & 0.5 & 0.1 & 0.4 \\
\hline TOTAL & 351 & 72 & 28 & 451 & 1.0 & 0.8 & 0.3 & 0.7 \\
\hline \multicolumn{9}{|l|}{ Ear, face and neck } \\
\hline Absence-stricture auditory canal & 50 & 8 & 6 & 64 & 0.1 & 0.1 & 0.1 & 0.1 \\
\hline Absent auricle & 4 & 1 & 0 & 5 & 0.0 & 0.0 & 0 & 0.0 \\
\hline Anomalies of face and neck & 38 & 5 & 2 & 45 & 0.1 & 0.1 & 0.0 & 0.1 \\
\hline Other ear anomalies & 65 & 12 & 7 & 84 & 0.2 & 0.1 & 0.1 & 0.1 \\
\hline TOTAL & 157 & 26 & 15 & 198 & 0.4 & 0.3 & 0.2 & 0.3 \\
\hline \multicolumn{9}{|l|}{ Cardiovascular system } \\
\hline Transposition of great vessels & 242 & 51 & 46 & 339 & 0.7 & 0.5 & 0.5 & 0.5 \\
\hline Tetralogy of Fallot & 160 & 33 & 20 & 213 & 0.5 & 0.3 & 0.2 & 0.3 \\
\hline Ventricular septal defect & 804 & 203 & 86 & 1093 & 2.3 & 2.1 & 0.9 & 1.7 \\
\hline Atrial septal defect & 821 & 194 & 102 & 1117 & 2.3 & 2.0 & 1.1 & 1.8 \\
\hline Heart valve anomalies & 502 & 119 & 60 & 681 & 1.4 & 1.3 & 0.6 & 1.1 \\
\hline Patent ductus arteriosus $>37$ weeks & 444 & 94 & 79 & 617 & 1.3 & 1.0 & 0.8 & 1.0 \\
\hline Coarctation of aorta & 211 & 48 & 28 & 287 & 0.6 & 0.5 & 0.3 & 0.5 \\
\hline Other anomalies of aorta & 127 & 27 & 8 & 162 & 0.4 & 0.3 & 0.1 & 0.3 \\
\hline Anomalies of pulmonary artery & 155 & 27 & 15 & 197 & 0.4 & 0.3 & 0.2 & 0.3 \\
\hline Other cardiovascular anomalies & 744 & 153 & 131 & 1028 & 2.1 & 1.6 & 1.4 & 1.6 \\
\hline TOTAL & 4210 & 949 & 575 & 5734 & 12.0 & 10.0 & 6.1 & 9.0 \\
\hline \multicolumn{9}{|l|}{ Respiratory system } \\
\hline Nose & 60 & 8 & 6 & 74 & 0.2 & 0.1 & 0.1 & 0.1 \\
\hline Larynx, trachea and bronchus & 37 & 7 & 3 & 47 & 0.1 & 0.1 & 0.0 & 0.1 \\
\hline Lung & 95 & 31 & 20 & 146 & 0.3 & 0.3 & 0.2 & 0.2 \\
\hline TOTAL & 192 & 46 & 29 & 267 & 0.5 & 0.5 & 0.3 & 0.4 \\
\hline \multicolumn{9}{|l|}{ Gastrointestinal system } \\
\hline Cleft palate only & 430 & 87 & 47 & 564 & 1.2 & 0.9 & 0.5 & 0.9 \\
\hline Cleft lip only & 144 & 38 & 24 & 206 & 0.4 & 0.4 & 0.3 & 0.3 \\
\hline Cleft palate and cleft lip & 216 & 49 & 47 & 312 & 0.6 & 0.5 & 0.5 & 0.5 \\
\hline Oesophageal atresia only & 17 & 2 & 2 & 21 & 0.0 & 0.0 & 0.0 & 0.0 \\
\hline Tracheo-oesophageal fistula (TOF) only & 20 & 4 & 4 & 28 & 0.1 & 0.0 & 0.0 & 0.0 \\
\hline Oesophageal atresia with TOF & 84 & 26 & 11 & 121 & 0.2 & 0.3 & 0.1 & 0.2 \\
\hline Atresia-stenosis of small intestine & 123 & 26 & 11 & 160 & 0.4 & 0.3 & 0.1 & 0.3 \\
\hline Atresia-stenosis of anus & 134 & 39 & 30 & 203 & 0.4 & 0.4 & 0.3 & 0.3 \\
\hline Other gastrointestinal anomalies & 483 & 106 & 24 & 613 & 1.4 & 1.1 & 0.3 & 1.0 \\
\hline TOTAL & 1651 & 377 & 200 & 2228 & 4.7 & 4.0 & 2.1 & 3.5 \\
\hline \multicolumn{9}{|l|}{ Genitourinary system } \\
\hline Anomalies of female genitals & 63 & 15 & 5 & 83 & 0.2 & 0.2 & 0.1 & 0.1 \\
\hline Undescended testis & 312 & 89 & 20 & 421 & 0.9 & 0.9 & 0.2 & 0.7 \\
\hline Hypospadias & 776 & 127 & 76 & 979 & 2.2 & 1.3 & 0.8 & 1.5 \\
\hline Epispadias & 5 & 3 & 1 & 9 & 0.0 & 0.0 & 0.0 & 0.0 \\
\hline Chordee & 149 & 43 & 8 & 200 & 0.4 & 0.5 & 0.1 & 0.3 \\
\hline Indeterminate sex-ambiguous genitalia & 55 & 10 & 8 & 73 & 0.2 & 0.1 & 0.1 & 0.1 \\
\hline Renal agenesis-dysgenesis & 174 & 30 & 20 & 224 & 0.5 & 0.3 & 0.2 & 0.4 \\
\hline Obstructive anomalies of renal pelvis and ureter & 700 & 158 & 37 & 895 & 2.0 & 1.7 & 0.4 & 1.4 \\
\hline Other genitourinary system anomalies & 677 & 142 & 61 & 880 & 1.9 & 1.5 & 0.6 & 1.4 \\
\hline TOTAL & 2911 & 617 & 236 & 3764 & 8.3 & 6.5 & 2.5 & 5.9 \\
\hline
\end{tabular}


Table 104. (Continued)

\begin{tabular}{|c|c|c|c|c|c|c|c|c|}
\hline \multirow[t]{2}{*}{ Diagnostic category } & \multicolumn{4}{|c|}{ No. conditions } & \multicolumn{4}{|c|}{ Rate/1,000 births } \\
\hline & 2003-2007 & 2008 & 2009 & 2003-2009 & 2003-2007 & 2008 & 2009 & 2003-2009 \\
\hline \multicolumn{9}{|l|}{ Musculoskeletal system } \\
\hline Congenital dislocation of the hips & 640 & 123 & 31 & 794 & 1.8 & 1.3 & 0.3 & 1.3 \\
\hline Talipes equinovarus & 370 & 82 & 31 & 483 & 1.1 & 0.9 & 0.3 & 0.8 \\
\hline Polydactyly & 485 & 95 & 60 & 640 & 1.4 & 1.0 & 0.6 & 1.0 \\
\hline Syndactyly & 123 & 24 & 13 & 160 & 0.4 & 0.3 & 0.1 & 0.3 \\
\hline Reduction deformities of limbs & 251 & 64 & 63 & 378 & 0.7 & 0.7 & 0.7 & 0.6 \\
\hline Craniosynostosis & 197 & 47 & 2 & 246 & 0.6 & 0.5 & 0.0 & 0.4 \\
\hline Diaphragmatic hernia & 129 & 30 & 25 & 184 & 0.4 & 0.3 & 0.3 & 0.3 \\
\hline Exomphalos & 66 & 15 & 26 & 107 & 0.2 & 0.2 & 0.3 & 0.2 \\
\hline Gastroschisis & 97 & 19 & 31 & 147 & 0.3 & 0.2 & 0.3 & 0.2 \\
\hline Other musculoskeletal anomalies & 733 & 165 & 118 & 1016 & 2.1 & 1.7 & 1.2 & 1.6 \\
\hline TOTAL & 3091 & 664 & 400 & 4155 & 8.8 & 7.0 & 4.2 & 6.5 \\
\hline Integumentary system & 242 & 58 & 12 & 312 & 0.7 & 0.6 & 0.1 & 0.5 \\
\hline Cystic hygroma & 48 & 14 & 8 & 70 & 0.1 & 0.1 & 0.1 & 0.1 \\
\hline \multicolumn{9}{|l|}{ Chromosomal anomalies } \\
\hline Trisomy 21 & 450 & 88 & 61 & 599 & 1.3 & 0.9 & 0.6 & 0.9 \\
\hline Trisomy 13 & 36 & 4 & 8 & 48 & 0.1 & 0.0 & 0.1 & 0.1 \\
\hline Trisomy 18 & 92 & 16 & 8 & 116 & 0.3 & 0.2 & 0.1 & 0.2 \\
\hline Turner syndrome & 72 & 15 & 5 & 92 & 0.2 & 0.2 & 0.1 & 0.1 \\
\hline Other chromosomal anomalies & 331 & 62 & 37 & 430 & 0.9 & 0.7 & 0.4 & 0.7 \\
\hline TOTAL & 981 & 185 & 119 & 1285 & 2.8 & 2.0 & 1.3 & 2.0 \\
\hline Situs inversus & 28 & 6 & 2 & 36 & 0.1 & 0.1 & 0.0 & 0.1 \\
\hline Congenital malformation syndromes & 191 & 34 & 27 & 252 & 0.5 & 0.4 & 0.3 & 0.4 \\
\hline Congenital cytomegalovirus infection & 1 & 2 & 1 & 4 & 0.0 & 0.0 & 0.0 & 0.0 \\
\hline Non-immune hydrops foetalis & 99 & 24 & 14 & 137 & 0.3 & 0.3 & 0.1 & 0.2 \\
\hline Other and unspecified anomalies & 486 & 149 & 20 & 655 & 1.4 & 1.6 & 0.2 & 1.0 \\
\hline TOTAL & 15425 & 3404 & 1798 & 20627 & 44.0 & 36.0 & 19.0 & 32.5 \\
\hline
\end{tabular}

Source: NSW Register of Congenital Conditions (HOIST). Centre for Epidemiology and Research, NSW Ministry of Health.

\# For 2003-2008, cases reported during pregnancy and up to one year of age are included. For 2009, cases reported during pregnancy or at birth are included.

\section{Infant characteristics}

In the period 2003-2009, a single condition was reported in $63.4 \%$ of infants, two conditions in $18.2 \%$, three conditions in $8.3 \%$, and four or more conditions in $10.1 \%$ of cases. The sex was male in $57.7 \%$ of infants, female in $41.8 \%$, indeterminate in $0.3 \%$ of infants, and was not stated for $0.2 \%$.

Congenital conditions were more common in preterm and post-term infants than infants born at term (Table 105). Congenital conditions were also more common in infants born of a multiple pregnancy than a singleton pregnancy: in
2003-2009, $1.8 \%$ of singleton babies, $2.7 \%$ of twins, and $3.3 \%$ of triplets were born with a congenital condition.

About $11 \%$ of infants born with congenital conditions died in the perinatal period, over half of which were stillbirths (Table 106). These figures comprise all cases of congenital conditions, including those where the cause of death may not be directly related to the congenital condition(s). By comparison, the perinatal mortality rate among all births reported to the NSW Perinatal Data Collection was less than 1\% in 2009 (see Chapter 4).

\section{Table 105. Cases of congenital conditions by gestational age, NSW 2003-2009\#}

\begin{tabular}{|c|c|c|c|c|c|c|c|c|c|}
\hline \multirow{3}{*}{$\begin{array}{l}\text { Gestational age } \\
\text { (weeks) }\end{array}$} & \multicolumn{9}{|c|}{ Year } \\
\hline & \multicolumn{2}{|c|}{ 2003-2007 } & \multicolumn{2}{|c|}{2008} & \multicolumn{2}{|c|}{2009} & \multicolumn{3}{|c|}{ 2003-2009 } \\
\hline & No. & $\%$ & No. & $\%$ & No. & $\%$ & No. & $\%$ & $\begin{array}{c}\text { No. of cases/ } \\
1,000 \text { births }\end{array}$ \\
\hline $20-27$ & 599 & 6.9 & 136 & 7.2 & 87 & 10.5 & 822 & 7.2 & 182.2 \\
\hline $28-31$ & 258 & 3.0 & 61 & 3.2 & 22 & 2.6 & 341 & 3.0 & 74.6 \\
\hline $32-36$ & 1155 & 13.2 & 228 & 12.1 & 120 & 14.4 & 1503 & 13.1 & 40.4 \\
\hline $37-41$ & 6313 & 72.4 & 1376 & 73.2 & 593 & 71.4 & 8282 & 72.4 & 14.3 \\
\hline $42+$ & 135 & 1.5 & 16 & 0.9 & 8 & 1.0 & 159 & 1.4 & 16.9 \\
\hline Not stated & 261 & 3.0 & 64 & 3.4 & 1 & 0.1 & 326 & 2.9 & 0 \\
\hline TOTAL & 8721 & 100.0 & 1881 & 100.0 & 831 & 100.0 & 11433 & 100.0 & 18.0 \\
\hline
\end{tabular}

\# For 2003-2008, cases reported during pregnancy and up to one year of age are included. For 2009, cases reported during pregnancy or at birth are included. 
Table 106. Cases of congenital conditions by pregnancy outcome, NSW 2003-2009\#

\begin{tabular}{|c|c|c|c|c|c|c|c|c|}
\hline \multirow[t]{3}{*}{ Pregnancy outcome } & \multicolumn{8}{|c|}{ Year } \\
\hline & \multicolumn{2}{|c|}{ 2003-2007 } & \multicolumn{2}{|c|}{2008} & \multicolumn{2}{|c|}{2009} & \multicolumn{2}{|c|}{ 2003-2009 } \\
\hline & No. & $\%$ & No. & $\%$ & No. & $\%$ & No. & $\%$ \\
\hline Stillbirth & 593 & 6.8 & 124 & 6.6 & 89 & 10.7 & 806 & 7.0 \\
\hline Liveborn/ neonatal death & 333 & 3.8 & 68 & 3.6 & 45 & 5.4 & 446 & 3.9 \\
\hline Liveborn/ postneonatal death & 42 & 0.5 & 15 & 0.8 & 17 & 2.0 & 74 & 0.6 \\
\hline Liveborn surviving & 7753 & 88.9 & 1674 & 89.0 & 680 & 81.8 & 10107 & 88.4 \\
\hline TOTAL & 8721 & 100.0 & 1881 & 100.0 & 831 & 100.0 & 11433 & 100.0 \\
\hline
\end{tabular}

\section{Maternal characteristics}

After 35 years of age, the incidence of congenital conditions increased with increasing maternal age (Table 107). While the rate of congenital conditions is higher in older women, the majority of births occur in younger women. In 2003-2009, $71.9 \%$ of babies with congenital conditions were born to women aged less than 35 years.
In 2003-2009, 414 babies of Aboriginal or Torres Strait Islander mothers were reported to have congenital conditions. The rate of congenital conditions among these babies was 22.6 per 1,000 compared with 17.2 per 1,000 for babies born to non-Aboriginal mothers.

Table 107. Cases of congenital conditions by maternal age, NSW 2003-2009\#

\begin{tabular}{|c|c|c|c|c|c|c|c|c|c|}
\hline \multirow[t]{3}{*}{ Maternal age (years) } & \multicolumn{9}{|c|}{ Year } \\
\hline & \multicolumn{2}{|c|}{ 2003-2007 } & \multicolumn{2}{|c|}{2008} & \multicolumn{2}{|c|}{2009} & \multicolumn{3}{|c|}{ 2003-2009 } \\
\hline & No. & $\%$ & No. & $\%$ & No. & $\%$ & No. & $\%$ & $\begin{array}{c}\text { No. of cases/ } \\
1,000 \text { births }\end{array}$ \\
\hline Under 20 & 351 & 4.0 & 75 & 4.0 & 46 & 5.5 & 472 & 4.1 & 20.1 \\
\hline $20-24$ & 1198 & 13.7 & 252 & 13.4 & 112 & 13.5 & 1562 & 13.7 & 17.7 \\
\hline $25-29$ & 2132 & 24.4 & 409 & 21.7 & 205 & 24.7 & 2746 & 24.0 & 16.0 \\
\hline $30-34$ & 2649 & 30.4 & 553 & 29.4 & 239 & 28.8 & 3441 & 30.1 & 16.2 \\
\hline $35-39$ & 1477 & 16.9 & 379 & 20.1 & 180 & 21.7 & 2036 & 17.8 & 17.6 \\
\hline $40-44$ & 377 & 4.3 & 105 & 5.6 & 44 & 5.3 & 526 & 4.6 & 23.3 \\
\hline $45+$ & 32 & 0.4 & 6 & 0.3 & 5 & 0.6 & 43 & 0.4 & 38.5 \\
\hline Not stated & 505 & 5.8 & 102 & 5.4 & 0 & 0.0 & 607 & 5.3 & 0.0 \\
\hline TOTAL & 8721 & 100.0 & 1881 & 100.0 & 831 & 100.0 & 11433 & 100.0 & 18.0 \\
\hline
\end{tabular}




\section{Congenital conditions among terminations of pregnancy, spontaneous abortions and unknown outcomes of pregnancy}

The number of terminations of pregnancy reported to the Register increased from 313 in 2003 to 354 in 2009 (Table 108). The number of terminations of pregnancy for 2009 is expected to increase as pregnancy outcomes for babies with conditions detected during pregnancy in 2009 continue to be followed-up.

Of the 2,304 terminations of pregnancy reported in 2003$2009,1,830$ (79.4\%) were associated with a chromosomal anomaly, the most common of which was Trisomy 21 (Down syndrome), and 171 (7.4\%) were associated with a neural tube defect (Table 109).

For spontaneous abortions, cytogenetic analysis is only carried out in cases of habitual abortion; the numbers presented, therefore, underestimate the number of spontaneous abortions that occur due to congenital conditions. Descriptions of some diagnostic terms used here are included in Appendix 1.

Table 108. Pregnancies with fetuses affected by congenital conditions resulting in spontaneous termination, spontaneous abortion or unknown outcome, NSW 2003-2009

\begin{tabular}{|c|c|c|c|c|c|c|c|c|}
\hline \multirow[t]{3}{*}{ Pregnancy outcome } & \multicolumn{8}{|c|}{ Year } \\
\hline & 2003 & 2004 & 2005 & 2006 & 2007 & 2008 & 2009 & 2003-2009 \\
\hline & No. & No. & No. & No. & No. & No. & No. & No. \\
\hline Spontaneous abortion & 233 & 298 & 322 & 363 & 334 & 330 & 237 & 2117 \\
\hline $\begin{array}{l}\text { Termination of pregnancy } \\
\text { less than } 20 \text { weeks gestation }\end{array}$ & 313 & 306 & 303 & 361 & 328 & 339 & 354 & 2304 \\
\hline Unknown outcome & 17 & 38 & 29 & 23 & 23 & 35 & 0 & 165 \\
\hline TOTAL & 563 & 642 & 654 & 747 & 685 & 704 & 591 & 4586 \\
\hline
\end{tabular}

Source: NSW Register of Congenital Conditions (HOIST). Centre for Epidemiology and Research, NSW Ministry of Health. 


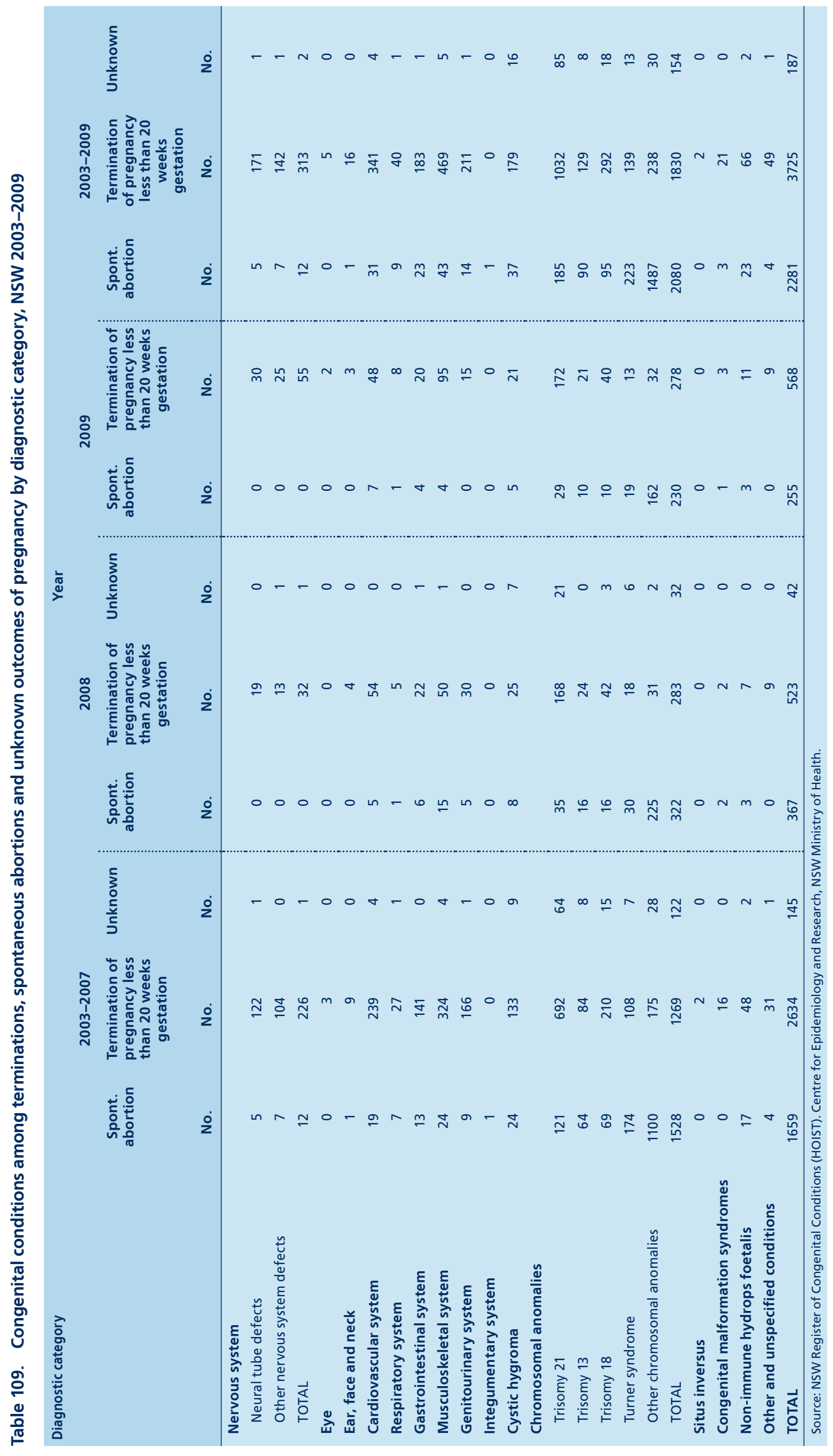




\section{Trends in selected congenital conditions}

Trends in a selection of common congenital conditions are shown in Table 110 and Figures 5 to 8. For 2003-2008, conditions reported up to one year of age are included. For 2009, conditions reported during pregnancy or at birth are included.

Over the period 2003-2009, the rate of neural tube defects has remained fairly stable at about 0.7 per 1,000 births. The reported number of live born and stillborn infants with neural tube defects was 39 in 2003 and 35 in 2009. The number of reported terminations of pregnancy was 28 in both 2003 and 2009 (Figure 5).

Over the period 2003-2008, the number of cases of isolated cleft palate ranged from 64 to 90 per year, and for total cleft lip (including cases of cleft lip and cleft palate) from 66 to 91 per year. Termination of pregnancy was usually associated with other conditions such as neural tube conditions, chromosomal anomalies, or multiple anomalies in addition to the cleft lip and/or cleft palate.
The reported number of live born and stillborn infants reported with chromosomal anomalies was 209 in 2003 and 185 in 2008. The number of reported terminations of pregnancy associated with chromosomal conditions rose from 245 in 2003 to 283 in 2008. The number of infants born with Down syndrome was 102 in 2003 and 85 in 2008, while the number of reported terminations of pregnancy associated with Down syndrome rose from 126 in 2003 to 168 in 2008.

In 2003, 17 live born infants were reported to have a diaphragmatic hernia, 4 babies were stillborn and there were no terminations of pregnancy associated with this condition. In 2008, there were 28 live born infants reported with a diaphragmatic hernia, 2 stillborn babies and 2 terminations of pregnancy (Figure 8)

\section{Table 110. Selected congenital conditions by year, NSW 2003-2009\#}

\begin{tabular}{|c|c|c|c|c|c|c|c|c|c|c|c|c|c|c|}
\hline \multirow[t]{2}{*}{ Condition } & \multicolumn{2}{|c|}{2003} & \multicolumn{2}{|c|}{2004} & \multicolumn{2}{|c|}{2005} & \multicolumn{2}{|c|}{2006} & \multicolumn{2}{|c|}{2007} & \multicolumn{2}{|c|}{2008} & \multicolumn{2}{|c|}{2009} \\
\hline & No. & $\begin{array}{c}\text { Rate/ } \\
1000\end{array}$ & No. & $\begin{array}{c}\text { Rate/ } \\
1000\end{array}$ & No. & $\begin{array}{l}\text { Rate/ } \\
1000\end{array}$ & No. & $\begin{array}{c}\text { Rate/ } \\
1000\end{array}$ & No. & $\begin{array}{c}\text { Rate/ } \\
1000\end{array}$ & No. & $\begin{array}{l}\text { Rate/ } \\
1000\end{array}$ & No. & $\begin{array}{c}\text { Rate/ } \\
1000\end{array}$ \\
\hline Neural tube defects & 67 & 0.8 & 58 & 0.7 & 66 & 0.7 & 66 & 0.7 & 74 & 0.8 & 72 & 0.8 & 63 & 0.7 \\
\hline Anencephalus & 18 & 0.2 & 16 & 0.2 & 19 & 0.2 & 15 & 0.2 & 26 & 0.3 & 18 & 0.2 & 13 & 0.1 \\
\hline Spina bifida & 46 & 0.5 & 35 & 0.4 & 40 & 0.4 & 45 & 0.5 & 42 & 0.4 & 45 & 0.5 & 45 & 0.5 \\
\hline Encephalocele & 7 & 0.1 & 8 & 0.1 & 8 & 0.1 & 8 & 0.1 & 8 & 0.1 & 9 & 0.1 & 9 & 0.1 \\
\hline Cleft palate & 88 & 1.0 & 74 & 0.9 & 90 & 1.0 & 64 & 0.7 & 74 & 0.8 & 82 & 0.9 & 43 & 0.5 \\
\hline Total cleft lip & 83 & 1.0 & 79 & 0.9 & 66 & 0.7 & 85 & 0.9 & 73 & 0.8 & 91 & 1.0 & 73 & 0.8 \\
\hline Hypospadias & 171 & 2.0 & 150 & 1.8 & 146 & 1.6 & 149 & 1.6 & 162 & 1.7 & 127 & 1.3 & 77 & 0.8 \\
\hline Limb reduction defects & 31 & 0.4 & 36 & 0.4 & 38 & 0.4 & 43 & 0.5 & 49 & 0.5 & 53 & 0.6 & 45 & 0.5 \\
\hline Chromosomal abnormalities & 454 & 5.3 & 447 & 5.3 & 409 & 4.6 & 480 & 5.2 & 454 & 4.8 & 468 & 4.9 & 397 & 4.2 \\
\hline Down syndrome & 228 & 2.7 & 233 & 2.8 & 209 & 2.3 & 252 & 2.8 & 218 & 2.3 & 256 & 2.7 & 233 & 2.5 \\
\hline Renal agenesis and dysgenesis & 67 & 0.8 & 82 & 1.0 & 73 & 0.8 & 86 & 0.9 & 63 & 0.7 & 70 & 0.7 & 44 & 0.5 \\
\hline Exomphalos & 19 & 0.2 & 28 & 0.3 & 15 & 0.2 & 22 & 0.2 & 25 & 0.3 & 22 & 0.2 & 30 & 0.3 \\
\hline Gastroschisis & 18 & 0.2 & 16 & 0.2 & 19 & 0.2 & 21 & 0.2 & 30 & 0.3 & 19 & 0.2 & 32 & 0.3 \\
\hline Diaphragmatic hernia & 21 & 0.2 & 30 & 0.4 & 28 & 0.3 & 25 & 0.3 & 28 & 0.3 & 32 & 0.3 & 30 & 0.3 \\
\hline
\end{tabular}


Figure 5. Neural tube anomalies: cases by year and pregnancy outcome, NSW 2003-2009\#

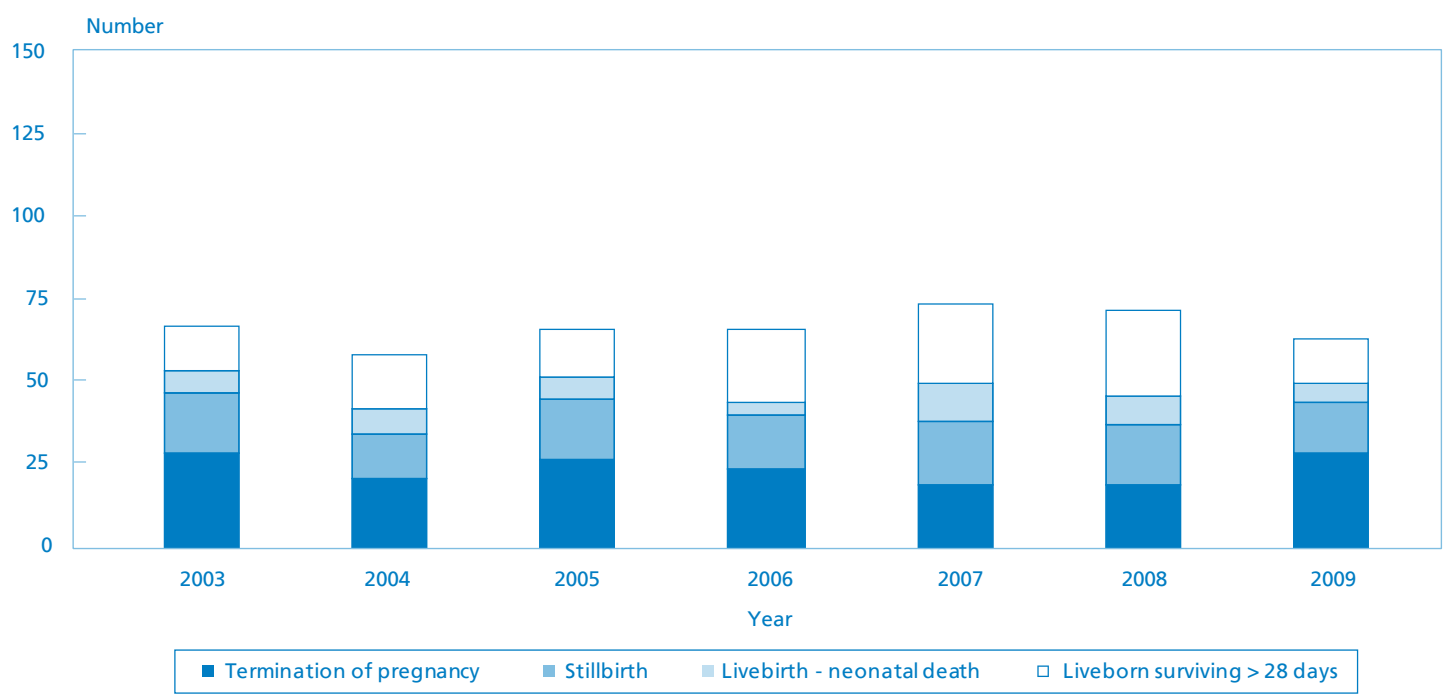

Source: NSW Register of Congenital Conditions (HOIST). Centre for Epidemiology and Research, NSW Ministry of Health.

\# For 2003-2008, cases reported during pregnancy and up to one year of age are included. For 2008, cases reported during pregnancy or at birth are reported.

Figure 6. Chromosomal anomalies: cases by year and pregnancy outcome, NSW 2003-2009\#

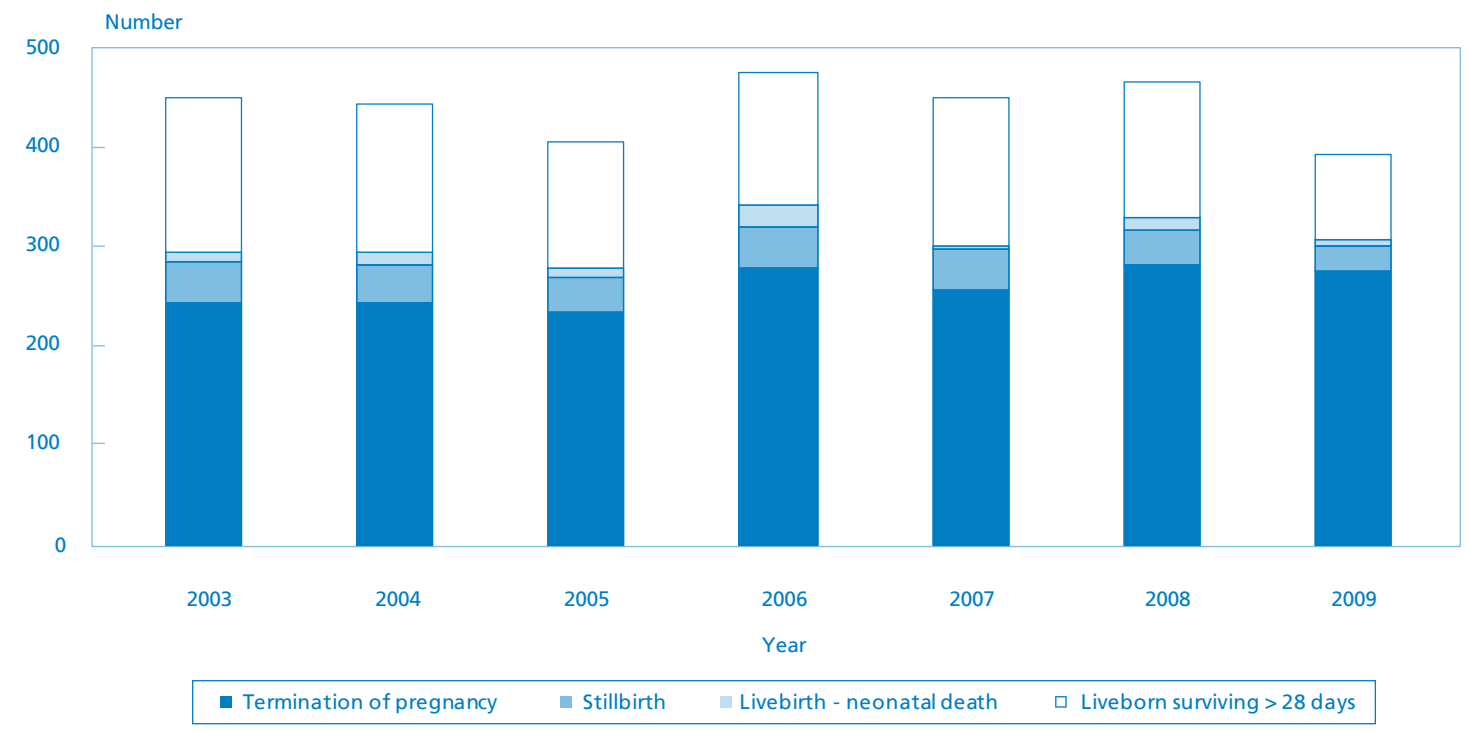

Source: NSW Register of Congenital Conditions (HOIST). Centre for Epidemiology and Research, NSW Ministry of Health

\# For 2003-2008, cases reported during pregnancy and up to one year of age are included. For 2009, cases reported during pregnancy or at birth are reported. 
Figure 7. Down syndrome: cases by year and pregnancy outcome, NSW 2003-2009\#

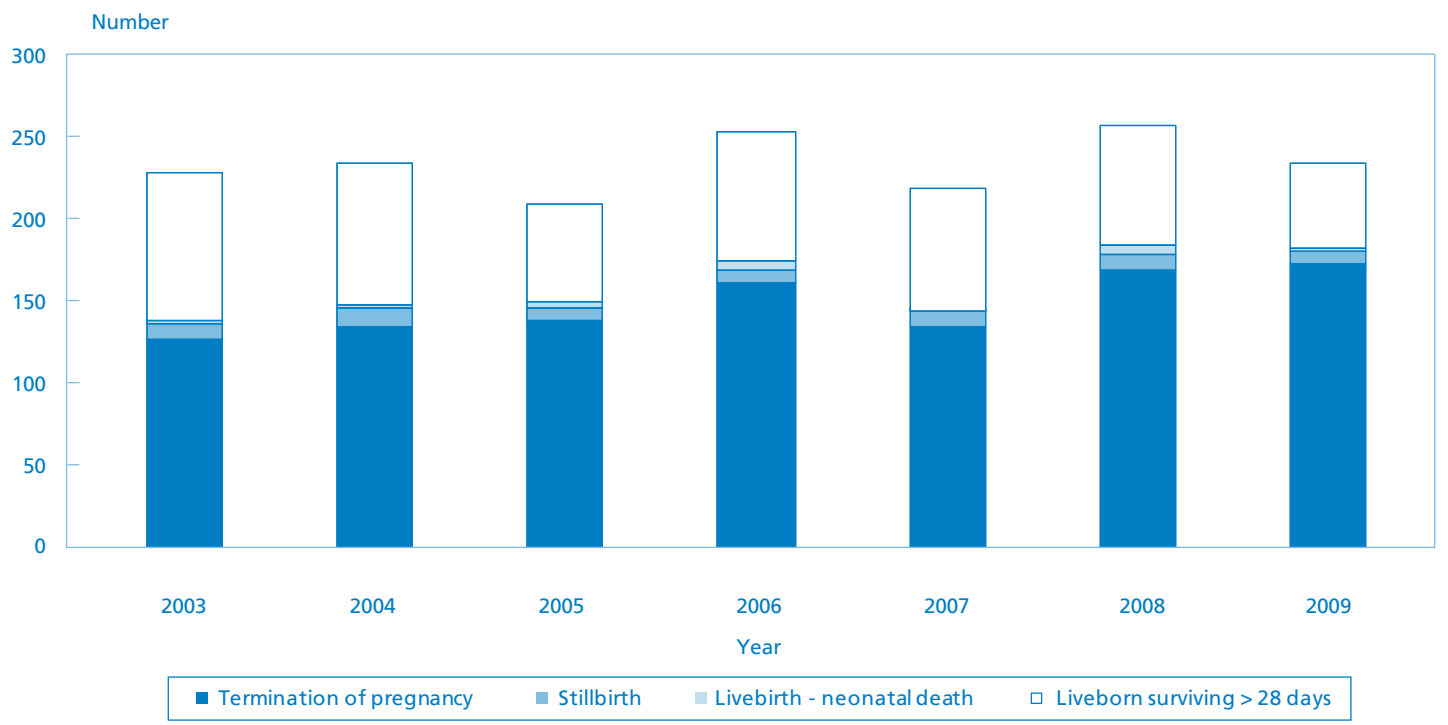

Source: NSW Register of Congenital Conditions (HOIST). Centre for Epidemiology and Research, NSW Ministry of Health.

\# For 2003-2008, cases reported during pregnancy and up to one year of age are included. For 2009, cases reported during pregnancy or at birth are reported.

Figure 8. Diaphragmatic hernia: cases by year and pregnancy outcome, NSW 2003-2009\#

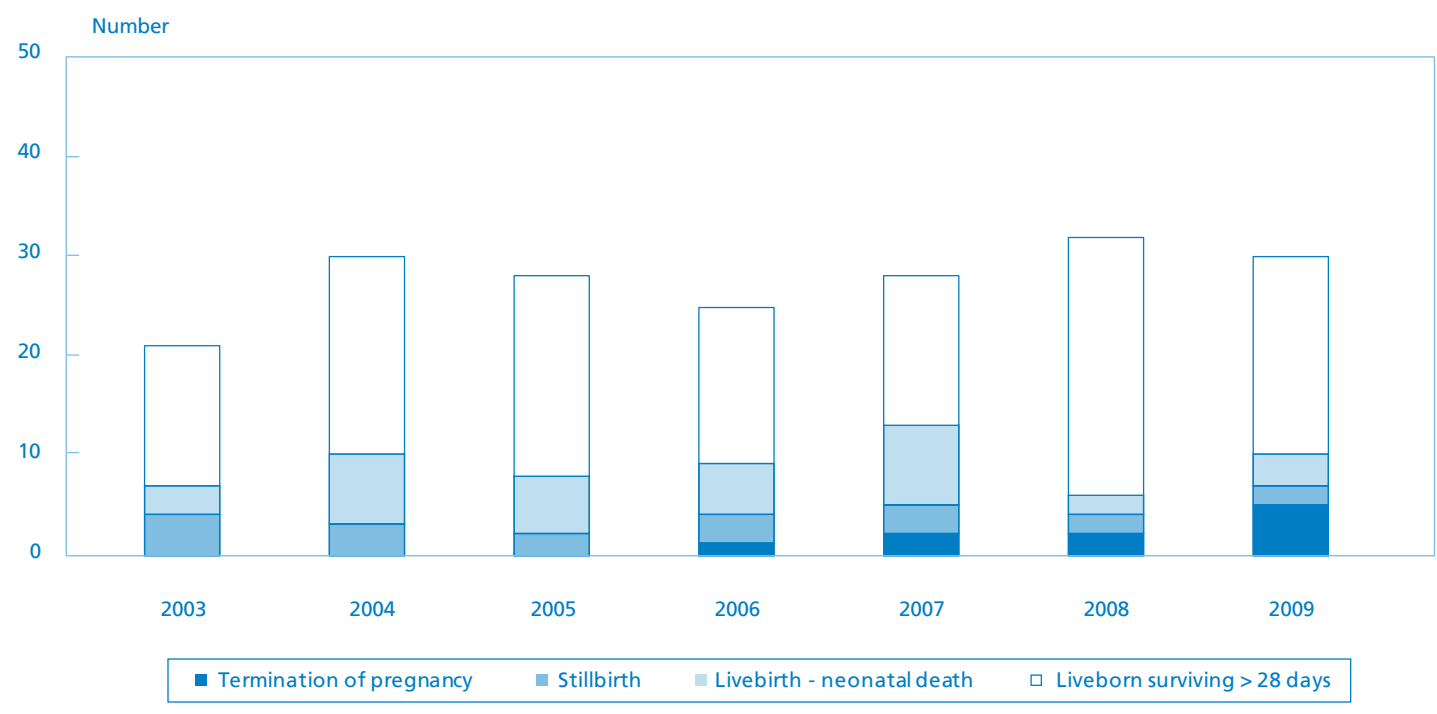

Source: NSW Register of Congenital Conditions (HOIST). Centre for Epidemiology and Research, NSW Ministry of Health

\# For 2003-2008, cases reported during pregnancy and up to one year of age are included. For 2009, cases reported during pregnancy or at birth are reported. 